\title{
In Memoriam: Professor Olga Mioduszewska
}

We are deeply saddened by the news of the tragic death of Professor Olga Mioduszewska, who was an outstanding pathomorphologist and hematopathologist. She co-created modern Polish pathology and the Pathology Department at the Institute of Oncology; she also made very important contribution to European and global hematopathology. She died on June $14^{\text {th }}, 2018$ at the age of 91 years, still full of life, despite many health problems with which she fought. One year ago she celebrated her $90^{\text {th }}$ birthday with a group of friends, remembering shared moments.

Olga Mioduszewska was born on February 3, 1927 in Vilnius as the daughter of Olga and Zenon Orłowski, in the family that had long tradition in medicine. Her father was Internal Medicine Professor at the Stefan Batory

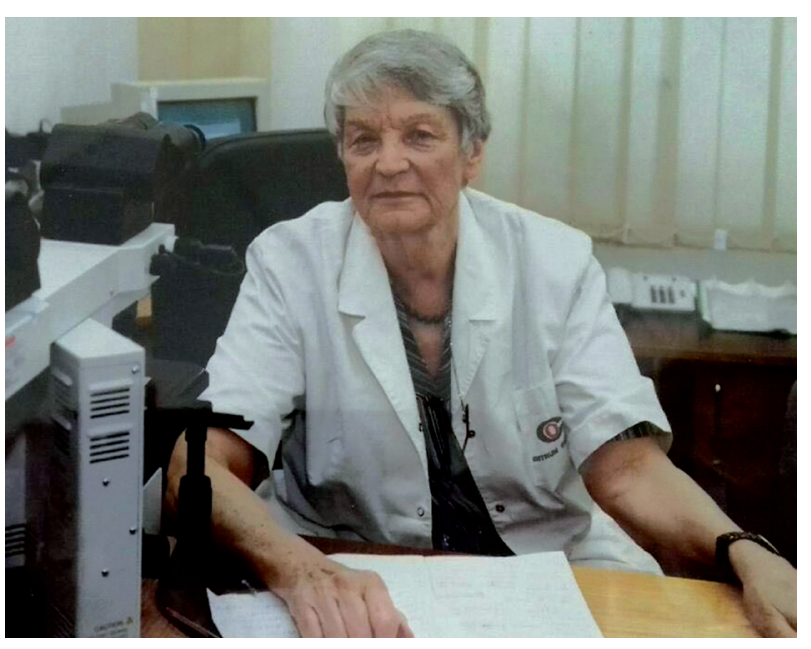

From September 1971 she was associated with the Oncology Center - Maria Sklodowska-Curie Institute in Warsaw, where she was the Head of the Special Techniques Laboratory. In 1978 at the conference in Katowice, Olga Mioduszewska met three famous hematopathologists who revolutionized lymphoma classifications: Professors Robert Lukes (California, USA), Robert Collins (Tennessee, USA) and Karl University in Vilnius and then pro-rector of this University. She finished her school education in Vilnius.

Olga Mioduszewska studied medicine at the Faculty of Medicine Lodz University 1945-1950 and started to work at the Department of Pathology already in 1949. She obtained the specialization in pathology in 1957. In 1958 Olga Mioduszewska received, as the second Polish scientist the Rockefeller Stipend award to carry research at the Finney-Howell Cancer Research Laboratory at the John Hopkins Hospital in Baltimore, Md, USA, under guidance of prof. George O. Gey. In 1962 she completed PhD with the thesis entitled "Influence of hormones on the malignant melanoma cells in culture" for which she received the Polish Academy of Sciences award 1963. She became Associate professor in 1965 at Lodz Oncology Center after completing the thesis "Influence of hormones on the breast cancer cells in culture". During the period between 1963 and 1971, she was the Head of the Histopathological Laboratory of the Oncology Center in Lodz.
Lennert (Kiel, Germany). She developed a close collaboration with all of them and was the first pathologist in Poland to introduce the immunopathological basics of lymphoma classification. She was the first representative of Central European Countries and the first woman in the European Lymphoma Club, which was established in Kiel, Germany under the guidance of Prof. Karl Lennert. This group developed the Kiel Classification of Malignant Lymphoma that later became the basis of contemporary lymphoma classifications. In 1979, she spent 3 months at the University of Southern California, Los Angeles, studying pathology and immunology of lymphomas.

During the 1980s, Prof. Mioduszewska introduced and developed scientific research on lymphomas in the Special Techniques Laboratory at the Maria-Sklodowska-Curie Institute of Oncology. Her Laboratory became a reference center for lymphoma in Poland. She became Professor in Pathology in 1984 and in 1985 she became the Head of the Department of Pathology of the Maria Sklodowska-Curie Institute of Oncology. Since 1996 she was the Head of the Immunopathology Laboratory. After retirement in 1997, she still worked at the Oncology Center in Warsaw until 2009.

Professor Mioduszewska was highly involved in teaching, organizing lymphoma courses at the Postgraduate Medical Center. She was since 1963 a member of the Committee for the Biology of Cancer at the Polish Academy of Science. Since 1977, she 
represented Poland in the International Committee for Coordination of Human Cancer Research. In the period of 1986-1990 she was the Scientific Secretary for the whole Oncology Center in Poland.

In 2004, Prof. Olga Mioduszewska received the Honorary Membership in the Polish Society of Pathology. She was a mentor and co-creator of the Polish Research Group for Lymphoma Studies.

Prof. Mioduszewska was the author or co-author of numerous scientific publications and textbook chapters on the immunopathology of lymphomas. PubMed list includes about 50 publications, the first one from 1955, the last one from 2009. Several later publications deal with the incidence of lymphomas in Poland and the Polish Lymphoma Registry. Many other publications are not listed in the official journal data bases. These are reviews or textbooks or textbook chapters aimed at pathology residents or hematologists interested in haematopathology.

Prof. Mioduszewska was the most appreciated expert on pathomorphology of lymphatic system diseases in Poland. She was not only an outstanding diagnostic pathomorphologist, but above all a wise physician - she vigilantly observed the principle of "first: do no harm" and always helped clinicians to find the optimal solution for the patient. She eagerly shared her impressive knowledge of the complexities of lymphatic cancer. She was distinguished by humility and criticism - above all in relation to her work, then to colleagues. What is more, she always had her own opinion, the feature which is not easily accepted by other people. She inspired her students to work creatively and was able to raise a passion for scientific research. She trained many resident pathologists and $\mathrm{PhD}$ students. Personally, we had the honor and privilege to be her students at the beginning of our medical careers, which made a deep impression on our future work. Prof. Mioduszewska was also much-loved by technical staff; she was always interested not only in their work but also in personal problems trying to help them if there was such a need.

She expressed her love through respect for people and concern for them. She loved the family, all beauty and nature. Although Professor Mioduszewska left this world, she leaves something good for everyone and in everyone who met her.

Prof. Anna Porwit Lund University Faculty of Medicine, Department of Clinical Sciences Division of Oncology and Pathology Lund, Sweden
Prof. Bogna Ziarkiewicz-Wróblewska Medical University of Warsaw Department of Pathology Warsaw, Poland

Prof. Jan Walewski Oncology Center

Maria-Sklodowska Curie Institute of Oncology Warsaw, Poland 